\title{
Severe obstructive sleep apnoea treated with long term nasal continuous positive airway pressure
}

\author{
RW FRITH, BR CANT \\ From the Department of Clinical Neurophysiology, Auckland Hospital, New Zealand
}

\begin{abstract}
Seven patients with the severe obstructive sleep apnoea syndrome were treated with nasal continuous positive airway pressure for from three to 22 months. This treatment reversed all symptoms due to the syndrome in every patient and continued to be used in five patients. One patient stopped treatment after eight months and subsequently remained incapacitated and another underwent tracheostomy at the time of transphenoidal hypophysectomy. Nasal continuous positive airway pressure is a safe, non-invasive treatment, which may be used in the presence of cardiac and respiratory failure. It is able fully to reverse upper airway obstruction and can be used at home on a long term basis.
\end{abstract}

The obstructive sleep apnoea syndrome, the most common cause of excessive daytime sleepiness, ' may produce recurrent headaches, hypertension, polycythaemia, heart failure, and cardiac arrhythmias. $^{23}$ The treatment of mild obstructive sleep apnoea consists of weight reduction and the avoidance of hypnotics and alcohol. In more severe cases various treatments have been reported including surgical reconstruction of the upper airway, ${ }^{45}$ a tongue restraining device, ${ }^{6}$ and medical treatment with protriptyline. ${ }^{78}$ In most cases, however, with appreciable nocturnal hypoxaemia and severe daytime hypersomnia, particularly when there are features of the Pickwickian syndrome, tracheostomy has been the treatment of choice. ${ }^{910}$ In 1981 Sullivan et al described reversal of obstructive sleep apnoea by continuous positive airway pressure through the nares," and subsequent reports have documented success $^{1213}$ and failure ${ }^{14}$ of this method. We report on seven patients treated successfully in hospital and then at home for periods of between three and 22 months.

\section{Methods}

Each patient underwent polysomnography on at least two nights before starting treatment, during

Address for reprint requests: Dr BR Cant, Department of Clinical Neurophysiology, Auckland Hospital, Auckland, New Zealand.

Accepted 19 June 1984 the initial treatment period, and intermittently thereafter. This consisted of continuous monitoring of electroencephalogram, electro-oculogram, electrocardiogram, nasal and oral airflow (using thermocouples), and chest and abdominal movements (using inductive spirometry). An ear oximeter (Hewlett-Packard 47201A) measured arterial oxygen saturation. Recordings were made on a Mingograf 16 channel electroencephalogram (Siemens-Elema). The recordings were scored using standard criteria. ${ }^{2}$ is Periods of obstructive apnoea occurred when the stopping of airflow at the nose and mouth was accompanied by continued respiratory effort and a drop in oxygen saturation. Obstructive hypopnoea, with diminished airflow at the nose and mouth, usually accompanied by snoring, was also identified.

TREATMENT PROTOCOL

After confirmation of severe obstructive sleep apnoea (oxygen saturation often dropping below $60 \%$ ) the patients started treatment with nasal continuous positive airway pressure using the method originally described by Sullivan et al "1 and illustrated in a later publication. ${ }^{13} \mathrm{~A}$ nasal mask was moulded from dental acrylic for each patient and sealed in place by a thin layer of silicone rubber (Silastic 382, Dow-Corning) (fig 1). Continuous positive, low pressure was produced with a flow of $300 \mathrm{l} / \mathrm{min}$ by a vortex blower connected to the nasal mask by roughly $3 \mathrm{~m}$ of tubing. The intranasal pressure was varied by altering the distal diameter of a tube of 


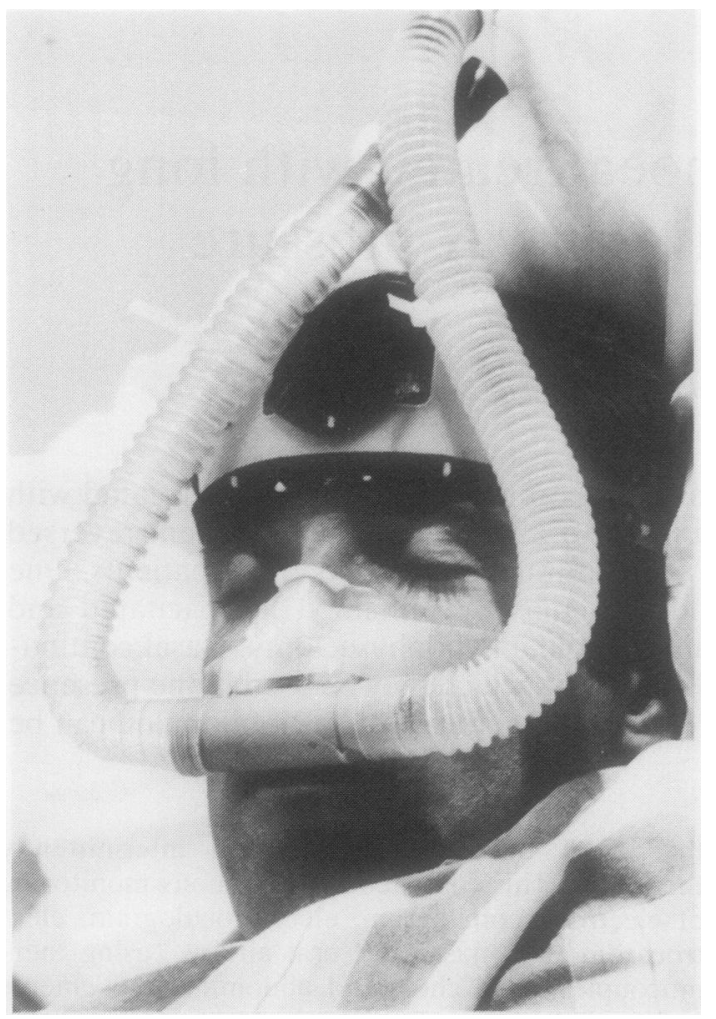

Fig 1 Mask used for nasal continuous positive airway pressure after application by a patient (case 5). The airflow is from his left and the intranasal pressure is regulated by adjusting the distal diameter of the tube on his right. The mask is held in place by rubber cement, an excess of which can be seen on the bridge of the nose, and a small strip of adhesive tape.

about $25 \mathrm{~cm}$ in length leading from the mask by using heat shrink tubing. It was increased until the abolition of obstruction to ventilation during sleep was shown by the maintenance of a satisfactory oxygen saturation, a normal nasal airflow, and an absence of paradoxical chest and abdominal movements during polysomnography. Intranasal pressure was measured through a small opening at the base of the mask with a calibrated manometer. The values quoted are mean pressure, which was also the pressure recorded when the patient stopped breathing. During the respiratory cycle the pressure varied by about $0.29 \mathrm{kPa}\left(3 \mathrm{~cm} \mathrm{H} \mathrm{H}_{2} \mathrm{O}\right)$ up or down. A thermocouple to measure respiratory airflow or a cannula to measure end tidal carbon dioxide can be inserted through the same orifice.

The patients started treatment in hospital and after several days' tuition were able to apply the device unaided. After discharge from hospital all continued to use the nasal continuous positive airway pressure at home.

\section{Case reports}

The patients reported on here, six men and one woman, were the most severely affected among those referred in 1982-3 for investigation and treatment of obstructive sleep apnoea. Each was offered a choice between nasal continuous positive airway pressure and tracheostomy and all gave informed consent.

CASE 1

A 48 year old Polynesian man presented with a seven year history of worsening daytime sleepiness, loud snoring, frequent nocturnal episodes of apnoea, an increase in weight from $86 \mathrm{~kg}$ to $130 \mathrm{~kg}$, and congestive heart failure. He had not worked for five years and had required recurrent admission to hospital. Examination showed no abnormality of the upper airways. He had polycythaemia, cardiomegaly (table 1), and daytime hypoventilation (table 2). Nocturnal polysomnography showed severe obstructive sleep apnoea. Frequent ventricular ectopic beats and runs of ventricular bigeminy occurred throughout the night. Nasal continuous positive airway pressure with an intranasal pressure of $0.78 \mathrm{kPa}(8 \mathrm{~cm}$ $\mathrm{H}_{2} \mathrm{O}$ ) reversed his upper airway obstruction on the first night, which permitted normal sleep. Initially there were minor dips in arterial oxygen saturation associated with periods of central and mixed apnoea but these had resolved within a week after starting treatment. Within two days daytime hypersomnia had stopped and appreciable diuresis occurred with rapid resolution of heart failure despite the withdrawal of digoxin and diuretic treatment. With nasal continuous positive airway pressure repeated nocturnal monitoring showed oxygen saturation between 90 and $95 \%$, and he remained asymptomatic. He was discharged from hospital after three weeks to continue treatment at home. A further polysomnogram three months after the start of treatment showed persistence of obstructive sleep apnoea when sleeping without nasal continuous positive airway pressure but normal sleep without episodes of obstruction or oxygen desaturation after application of nasal continuous positive airway pressure (fig 2). He continued to use this treatment at home for 22 months without difficulty. He lost $15 \mathrm{~kg}$ in weight, his polycythaemia resolved without venesection (haemoglobin $15.5 \mathrm{~g} / \mathrm{dl}$, packed cell volume 0.45 ), and his chest radiograph showed reduction in cardiac size (cardiothoracic ratio $=0.51)$. During 
Table 1 Characteristics of patients treated with nasal continuous positive airway pressure (CPAP)

\begin{tabular}{|c|c|c|c|c|c|c|c|}
\hline & \multicolumn{7}{|l|}{ Case No } \\
\hline & 1 & 2 & 3 & 4 & 5 & 6 & 7 \\
\hline Age (years) & 50 & 42 & 44 & 50 & 28 & 55 & 21 \\
\hline $\begin{array}{l}\text { Sex } \\
\text { Weight at start of treatment }\end{array}$ & $\mathbf{M}$ & $\mathbf{M}$ & M & $\mathbf{M}$ & $\mathbf{M}$ & $\mathbf{M}$ & $\mathrm{F}$ \\
\hline$(\mathrm{kg})$ & 130 & 115 & 121 & 93 & 54 & 110 & 169 \\
\hline Duration of symptoms (years) & 7 & 5 & 10 & 20 & 2 & 5 & \\
\hline $\begin{array}{l}\text { Haemoglobin at start of } \\
\text { treatment (g dl) } \\
\text { Presence of heart failure }\end{array}$ & $\begin{array}{l}22 \cdot 1 \\
\text { Right and left }\end{array}$ & $15 \cdot 5$ & $\begin{array}{l}14 \cdot 6 \\
\text { Right and left }\end{array}$ & $\begin{array}{l}16 \cdot 6 \\
\text { tLeft }\end{array}$ & $\begin{array}{l}\text { 19.0 } \\
\text { Right }\end{array}$ & $15 \cdot 3$ & $14 \cdot 8$ \\
\hline $\begin{array}{l}\text { Cardiothoracic ratio (postero } \\
\text { anterior chest radiograph) }\end{array}$ & 0.57 & $0 \cdot 5$ & 0.58 & 0.52 & $0 \cdot 51$ & $0 \cdot 48$ & $0 \cdot 45$ \\
\hline $\begin{array}{l}\text { Apnoea index (apnoea }+ \\
\text { hypopnoeahour) }\end{array}$ & & & & & & & \\
\hline & 38 & 67 & 44 & 59 & 46 & 58 & 85 \\
\hline $\begin{array}{l}\text { Mean duration of apnoea }(\mathrm{s}) \\
\text { Lowest oxygen saturation }(\%)^{*}\end{array}$ & $*<50$ & $\begin{array}{l}32 \\
52\end{array}$ & $\begin{array}{l}23 \\
<50\end{array}$ & $\begin{array}{l}45 \\
56\end{array}$ & $\begin{array}{l}24 \\
<50\end{array}$ & $\begin{array}{l}41 \\
<50\end{array}$ & $\begin{array}{l}24 \\
<50\end{array}$ \\
\hline Cardiac arrhythmias & $\begin{array}{l}\text { VEPBs, bigeminy } \\
\text { bradycardia }\end{array}$ & $\begin{array}{l}\text { Sinus arrest, } \\
\text { bradycardia }\end{array}$ & $\begin{array}{l}\text { VEPBs, } \\
\text { bradycardia }\end{array}$ & Bradycardia & $\begin{array}{l}\text { VEPBs, } \\
\text { bradycardia }\end{array}$ & $\begin{array}{l}\text { VEPBs, } \\
\text { bradycardia }\end{array}$ & Bradycardia \\
\hline $\begin{array}{l}\text { CPAP intranasal pressure } \\
\left(\mathrm{cm} \mathrm{H}_{2} \mathrm{O}\right) \\
\text { Duration of treatment }\end{array}$ & - & $6 \cdot 5$ & $8 \cdot 5$ & 8 & 8 & 8 & 8 \\
\hline (months) & 22 & 18 & 8 & 3 & 7 & 7 & 7 \\
\hline Outcome & $\begin{array}{l}\text { Continued } \\
\text { treatment; } \\
\text { working; } \\
\text { asymptomatic }\end{array}$ & $\begin{array}{l}\text { Continued } \\
\text { treatment; } \\
\text { working; } \\
\text { asymptomatic }\end{array}$ & $\begin{array}{l}\text { Stopped } \\
\text { CPAP; } \\
\text { chronic } \\
\text { invalid }\end{array}$ & $\begin{array}{l}\text { Stopped CPAP; } \\
\text { tracheostomy }\end{array}$ & $\begin{array}{l}\text { Continued treatment } \\
\text { Working: } \\
\text { asymptomatic }\end{array}$ & $\begin{array}{l}\text { Continued } \\
\text { treatment; } \\
\text { retired; } \\
\text { asymptomatic }\end{array}$ & $\begin{array}{l}\text { Continued } \\
\text { treatment; } \\
\text { asymptomatic }\end{array}$ \\
\hline Other medical problems & & $\begin{array}{l}\text { Pacemaker; } \\
\text { ischaemic } \\
\text { heart disease }\end{array}$ & $\begin{array}{l}\text { Chronic } \\
\text { bronchitis }\end{array}$ & $\begin{array}{l}\text { Acromegaly: } \\
\text { cardiomyopathy; } \\
\text { mitral } \\
\text { incompetence }\end{array}$ & $\begin{array}{l}\text { Neurofibromatosis; } \\
\text { kyphoscoliosis; } \\
\text { coarctation of aorta; } \\
\text { polycythaemia } \\
\text { (venesected) }\end{array}$ & $\begin{array}{l}\text { Polycythaemia } \\
\text { (venesected) }\end{array}$ & $\begin{array}{l}\text { Type } 1 \text { insulin } \\
\text { resistance } \\
\text { syndrome }\end{array}$ \\
\hline
\end{tabular}

${ }^{*} \mathrm{SaO}_{2}$ readings inaccurate below $50 \%$.

VEPB - ventricular ectopic premature beats.

the day his arterial oxygen pressure increased to $75 \mathrm{~mm} \mathrm{Hg}(10 \mathrm{kPa})$ and arterial carbon dioxide pressure decreased to $40 \mathrm{~mm} \mathrm{Hg}(5 \cdot 3 \mathrm{kPa})$. He was able to walk 3-5 km daily without limitation and he returned to manual work in a factory.

CASE 2

A 42 year old Polynesian man presented with a five year history of excessive daytime sleepiness. After admission to another hospital for ischaemic cardiac pain the obstructive sleep apnoea syndrome was diagnosed when recurrent nocturnal apnoeic episodes associated with bradycardia or asystole

Table 2 Respiratory function for six of seven patients treated with nasal continuous positive airway pressure

\begin{tabular}{lllll}
\hline Case $\mathrm{No}$ & $\begin{array}{l}\mathrm{PaO}_{2}^{\dagger} \\
\left(\mathrm{mm}^{\dagger} \mathrm{Hg}\right)\end{array}$ & $\begin{array}{l}\mathrm{PaCO}_{2}^{\dagger} \\
\left(\mathrm{mm} \mathrm{Hg}^{\dagger}\right)\end{array}$ & $\begin{array}{l}\mathrm{FEV} \\
(\mathrm{ml})\end{array}$ & $\begin{array}{l}\mathrm{VC} \\
(\mathrm{ml})\end{array}$ \\
\hline 1 & 43 & 56 & 2220 & 3260 \\
2 & 68 & 46 & 2100 & 2770 \\
3 & 46 & 53 & 2150 & 2900 \\
5 & 48 & 66 & 920 & 1180 \\
6 & 66 & 40 & 3040 & 3850 \\
$7^{*}$ & 84 & 34 & & \\
\hline
\end{tabular}

†Awake, breathing room air.

${ }^{*}$ Respiratory function tests were incomplete in the endocrinological cases (cases 4 and 7).

Conversion: traditional to SI units $-\mathrm{PaO}_{2}$ and $\mathrm{PaCO}_{2}: 1 \mathrm{~mm} \mathrm{Hg} \approx$ $0 \cdot 13 \mathrm{kPa}$. lasting for up to 20 seconds were observed. A cardiac pacemaker was inserted and weight loss of $23 \mathrm{~kg}$ was achieved by dieting. When assessed five months later his daytime symptoms had improved slightly and his angina had been reduced in severity by drugs. Examination showed only moderate obesity. There was no polycythaemia and daytime arterial carbon dioxide tension $\left(\mathrm{PaCO}_{2}\right)$ was normal. Radiography and diaphragmatic screening confirmed long standing paralysis of the right diaphragm with no obvious cause. Overnight polysomnography showed severe obstructive sleep apnoea. Treatment with nasal continuous positive airway pressure was started with an intranasal pressure of $66.3 \mathrm{kPa} \quad\left(6.5 \mathrm{~cm} \quad \mathrm{H}_{2} \mathrm{O}\right)$. Repeated nocturnal monitoring showed that this treatment prevented obstruction and resulted in a nocturnal arterial oxygen saturation of about $95 \%$. He was discharged after five days' treatment and continued to use nasal continuous positive airway pressure at home without difficulty for 18 months.

Coronary angiography showed severe coronary artery disease and he underwent coronary artery vein grafting; he remained intubated for the first 24 hours after the operation and resumed the use of nasal continuous positive airway pressure on the second postoperative night. During this time the 

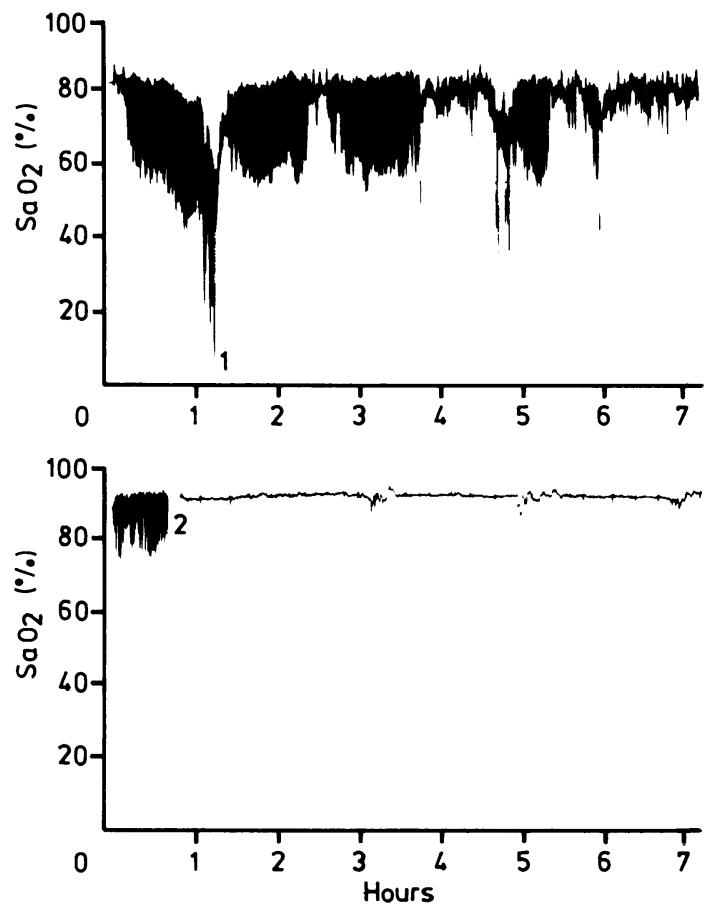

Fig 2 Recordings of nocturnal oxygen saturation during sleep (case 1). (Top) Diagnostic night; $I$ = patient woken owing to severe desaturation. (Bottom) Treatment night; initially obstructive episodes occurred; 2 = application of nasal continuous positive airway pressure.

inspired oxygen content was maintained at $35 \%$ (the level normally used after cardiac surgery) by placing oxygen cannulas in the intake port of the blower motor. After this he was asymptomatic, was able to continue full employment, and returned to refereeing junior grade rugby football. There was no significant improvement in his arterial blood gases during the day, however $\left(\mathrm{PaO}_{2} 63 \mathrm{~mm} \mathrm{Hg}(8.4 \mathrm{kPa})\right.$, $\left.\mathrm{PaCO}_{2} 46 \mathrm{~mm} \mathrm{Hg}(6 \cdot 1 \mathrm{kPa})\right)$.

CASES 3-5

Four other patients with the severe obstructive sleep apnoea syndrome also used nasal continuous positive airway pressure at home for at least three months.

Case $3 \mathrm{~A}$ man had been unemployed for three years because of shortness of breath, daytime sleepiness, and morning headaches. In addition to obstructive sleep apnoea with daytime hypoventilation he had obstructive airway disease partially relieved by inhalation of salbutamol and a history of recurrent respiratory infection. He had clinical and radiological evidence of congestive cardiac failure. He was successfully established on nasal continuous positive airway pressure but because of a skin reaction to the rubber compound a firmly fitting paediatric anaesthetic mask had to be substituted for the moulded nose mask. He found this method uncomfortable and, although nasal continuous positive airway pressure relieved his daytime sleepiness and headaches and resulted in some improvement in his shortness of breath, he failed to use the treatment continuously and after eight months stopped its use; he also refused tracheostomy. He remained disabled and declined further treatment.

Case 4 A patient with acromegaly used nasal continuous positive airway pressure successfully at home for three months before undergoing transphenoidal resection of a pituitary adenoma. As nasal continuous positive airway pressure was contraindicated during the postoperative period a tracheostomy was made at the time of his operation and this continued to provide alleviation of his obstructive sleep apnoea. Although he had used nasal continuous positive airway pressure regularly before operation, he found it emotionally stressful and could not envisage using the method on a long term basis. He had recurrent problems with his tracheostomy including stoma infection and mucous plugging of the tube at night. He remained uncertain about the best form of treatment.

Case 5 A man with neurofibromatosis, thoracic kyphoscoliosis, chest wall deformity, and a repaired coarctation of the aorta was established on nasal continuous positive airway pressure because of severe obstructive sleep apnoea complicated by right heart failure, daytime hypercapnia, and polycythaemia. After this he remained asymptomatic, his haemoglobin concentration remained normal without venesection, and he was able to cope with a full time job. During the day $\mathrm{PaO}_{2}$ increased to $83 \mathrm{~mm} \mathrm{Hg}(11 \mathrm{kPa})$ and $\mathrm{PaCO}_{2}$ decreased to $48 \mathrm{~mm} \mathrm{Hg}(5.8 \mathrm{kPa})$ despite the deformity of his chest. He travelled overseas on vacation for two weeks taking his nasal continuous positive airway pressure equipment with him.

CASE 6

A man required venesection for polycythaemia secondary to severe obstructive sleep apnoea. After starting nasal continuous positive airway pressure he became asymptomatic and his haemoglobin concentrations remained normal without further venesection.

CASE 7

A woman with insulin resistance, acanthosis nigricans, features resembling acromegaly, and virilisa- 
tion (type 1 insulin resistance syndrome) had severe obstructive sleep apnoea. This was thought to be aggravated by severe tonsillar enlargement. Because of her gross obesity and other medical problems, removal of her tonsils was thought to be too hazardous. She therefore started treatment with nasal continuous positive airway pressure, which produced appreciable improvement in nocturnal oxygen saturation. Several minor obstructive episodes occurred with occasional dips in oxygen saturation below $90 \%$, but her sleep was uninterrupted, and treatment produced appreciable improvement in her symptoms; she continued to use nasal continuous positive airway pressure at home while attempting to lose weight sufficient to permit tonsillectomy.

We did not identify any serious medical complications of this treatment. During upper respiratory tract infection, especially with nasal blockage and rhinorrhoea, nasal continuous positive airway pressure can be uncomfortable; in these circumstances we advised patients to use regular nasal decongestants and resume nasal continuous positive airway pressure as the symptoms resolve. In the patients who continued to use nasal continuous positive airway pressure the treatment was well accepted by family members; the quiet hum of the blower motor was preferred to the loud snoring of before treatment.

\section{Discussion}

Symptoms of severe obstructive sleep apnoea can be incapacitating, especially when they include features of the Pickwickian syndrome. Nasal continuous positive airway pressure is a successful way of treating this disease; in six of our patients it was well tolerated and has been used at home for up to 22 months. It resulted in reversal of nocturnal obstructive episodes in all patients, and its long term benefits have been shown by the rapid reversal of heart failure and polycythaemia in those patients more severely affected by the disease. In the two patients with severe alveolar hypoventilation who continued treatment there was an appreciable improvement in daytime respiratory function.

The technique described by Sullivan et al works well'"; application of the equipment was mastered by each patient within a few days. The use of a moulded nose mask held in place with silicone rubber is preferable to masks fixed with tapes or harnesses as there is no pressure against the nose or face and the sealing prevents leakage around the edges of the mask. Monitoring of respiratory variables is possible through a small orifice in the base of the mask. A blower motor that produces high rates of flow at low pressure is an important part of the sys- tem; dynamic resistance of the circuit must be low, and positive nasal airway pressure must be maintained during inspiration to prevent the choking and feelings of suffocation reported in three of four patients in a previous trial. ${ }^{14} \mathrm{~A}$ humidifier, as used in the system described by Rapoport et al, ${ }^{12}$ is unnecessary as the total transnasal airflow is normal and the pump uses room air. In addition, a humidifier makes the apparatus more cumbersome and may result in accumulation of condensate in the tubing.

No major problems with compliance by the patients who continued to use the treatment were found. A disadvantage of nasal continuous positive airway pressure when compared with tracheostomy is that its continued use requires a positive decision about compliance that must be made by the patient each night; he needs to remain well motivated and be prepared to spend a few minutes required to apply the mask. All of our patients stopped the treatment for periods varying between several days and several weeks during the first few months of treatment, but the recurrence of symptoms encouraged them to restart it. Another disadvantage of nasal continuous positive airway pressure is that upper respiratory tract infections interfere with its use. During periods of nasal blockage obstructive sleep apnoea tends to be more severe ${ }^{16}$ whereas patients with a tracheostomy are not affected.

Nasal continuous positive airway pressure will probably not be ideal as a long term treatment for all patients with severe obstructive sleep apnoea. We believe, however, that patients with severe disease should be treated with nasal continuous positive airway pressure in the first instance as it is as immediately successful as tracheostomy and avoids the risks of an anaesthetic and operation in a patient who may be obese and severely ill with respiratory and cardiac failure. If it is not well tolerated, or if it is clear that long term compliance is unlikely to occur, other forms of treatment may be used. The use of nasal continuous positive airway pressure thus provides the patient with a choice about long term treatment and allows time to plan for tracheostomy or uvulopalatopharyngoplasty if one of these methods is eventually chosen. Though it has not been the case in our patients, nasal continuous positive airway pressure may induce remission of symptoms within a few weeks after starting treatment, and the treatment may then be withdrawn, thereby avoiding the need for either tracheostomy or long term nasal continuous positive airway pressure. ${ }^{13}$

Nasal continuous positive airway pressure reverses all symptoms of the obstructive sleep apnoea syndrome, and our patients used this treatment at home for long periods. The patients continuing to use nasal continuous positive airway pressure 
expressed a strong desire to remain with this treatment rather than consider invasive forms of treatment. In selected patients with severe disease we believe that this method is the treatment of choice.

We thank Miss S Russell for technical help. This work was supported by Aukland Medical Research Foundation and the National Heart Foundation of New Zealand.

\section{References}

1 Coleman RM, Roffward HP, Kennedy SJ, et al. Sleep-wake disorders based on a polysomnographic diagnosis. JAMA 1982;247:997-1003.

2 Guilleminault C, Dement WC, eds. Sleep apnea syndromes. New York: Liss, 1978.

3 Miller WP. Cardiac arrhythmias and conduction disturbances in the sleep apnea syndrome. Am J Med 1982;73:317-21.

4 Olsen KD, Suh KW, Staats BA. Surgically correctable causes of sleep apnea syndrome. Otolaryngol Head Neck Surg 1981;89:726-31.

5 Fujita S, Conway W, Zorick F, Roth T. Surgical correction of anatomic abnormalities in obstructive sleep apnea syndrome: uvulopalatopharyngoplasty. Otolaryngol Head Neck Surg 1981;89:923-34.

6 Cartwright RD, Samelson CF. The effects of a nonsurgical treatment for obstructive sleep apnea. JAMA 1982;248: 705-9.

7 Conway WA, Zorick F, Piccione P, Roth T. Protrip- tyline in the treatment of sleep apnoea. Thorax 1982;37:49-53.

8 Brownell LG, West P, Sweatman P, Acres JC, Kryger MH. Protriptyline in obstructive sleep apnea. $N$ Engl J Med 1982;307: 1037-42.

9 Motta J, Guilleminault C, Schroeder JS, Dement WC. Tracheostomy and hemodynamic changes in sleepinduced apnea. Ann Intern Med 1978;89:454-8.

10 Guilleminault C, Simmons FB, Motta J, et al. Obstructive sleep apnea syndrome and tracheostomy. Acta Intern Med 1981;141:985-8.

11 Sullivan CE, Issa FG, Berthon-Jones M, Eves L. Reversal of obstructive sleep apnoea by continuous positive airway pressure applied through the nares. Lancet 1981;i:862-5.

12 Rapoport DM, Sorkin B, Garay SM, Goldring RM. Reversal of the "Pickwickian syndrome" by long-term use of nocturnal nasal-airway pressure. $N$ Engl J Med 1982;307:931-3.

13 Sullivan CE, Berthon-Jones M, Issa FG. Remission of severe obesity-hypoventilation syndrome after shortterm treatment during sleep with nasal continuous positive airway pressure. Am Rev Respir Dis 1983; 128: 177-81.

14 Wagner DR, Pollock CP, Weitzman ED. Nocturnal nasal-airway pressure for sleep apnea. $N$ Engl J Med 1983;308:461-2.

15 Rechtschaffen A, Kales A, eds. A manual of standardized terminology, techniques and scoring systems for sleep stages of human subjects. Los Angeles: University of California, Brain Information Service/Brain Research Institute, 1968.

16 Zwillich CW, Pickett C, Hanson FN, Weil JV. Disturbed sleep and prolonged apnea during nasal obstruction in normal men. Am Rev Respir Dis 1981;124: 158-60. 